\section{AFE \\ ARCHIVES \\ of} chessy Powered by iThenticate
DE

DE GRUYTER

OPEN

ISSN (2299-2944)

Volume 16

Issue 4/2016

\title{
Assessment of Durability of the Toothed Segment Based on FEM Analysis and Low Fatigue Cycle Test
}

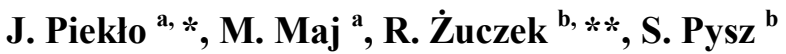 \\ ${ }^{a}$ AGH University of Science and Technology, Faculty of Foundry Engineering, Department of Foundry Process \\ Engineering, 23 Reymonta Str., 30-059 Cracow, Poland \\ ${ }^{\mathrm{b}}$ Foundry Research Institute, 73 Zakopiańska Str., 30-418 Cracow, Poland \\ Corresponding author. E-mail address *jarekp60@agh.edu.pl, **robert.zuczek@iod.krakow.pl
}

Received 30.04.2016; accepted in revised form 23.06.2016

\begin{abstract}
The development of a novel design for the toothed segment of drive transmission in longwall shearer is expected to significantly reduce the cost of individual components of the feed system and the related work of repair and renovations, increasing at the same time the safety of mine repair teams.

The conducted experimental and numerical analysis of the state of stress and strain in the innovative design of the toothed segment has enabled estimating the maximum effort of the developed structure. Based on the results of fundamental mechanical studies of the cast L20HGSNM steel and fatigue tests combined with the numerical stress/strain analysis, the fatigue life curve was plotted for the examined casting of the rack.
\end{abstract}

Keywords: Design life cycle, Fatigue analysis, Fatigue criteria, Low Fatigue Cycle test

\section{Introduction}

During coal exploitation, the longwall mining machine moves on a conveyor by meshing of the drive wheel teeth with a rackand-pinion arrangement. Under the prevailing operating conditions, the whole system is exposed to a rapid wear. The accelerated wear of teeth leads to frequent replacement of the expensive element, which is the drive wheel of longwall shearer, thus generating high operating costs. To increase the efficiency of coal exploitation and provide better work safety conditions during the longwall shearer operation, studies have been undertaken to develop a new feed system for the mining machinery. Of key importance in the development of new solutions and their subsequent practical implementation is the analysis of design, material and manufacturing process. A suitable tool to study and implement the preset objectives is the Integrated Computational Materials Engineering (ICME). [1]

The feed system currently used in the shearers operating in Polish coal mines is an Eicotrack system, in which segments of the racks are rigidly fixed to the brackets. [2] The teeth of the vertically positioned drive wheel of the longwall shearer haulage system mesh the horizontally positioned pins of the rack, forcing change in the location of the combine. On the rack is travelling by sliding movement the combine guide, ensuring constant conditions of engagement between the drive wheel and the rack. Due to a large number of the meshing cycles, the wheel is rapidly worn out. This forces the downtime necessary for replacement of this element, which generates losses because at that time the combine is not working. [2] A key problem has therefore become 
how to extend the combine operating period through extended time of the gear operation.

As a solution to the problem, an innovative Flextrack system has been developed. It is based on single modular teeth placed in a guide channel, which is also of a modular structure, thus being applicable in any arbitrary place along the entire route of the combine operation. The numerical computations performed in an ANSYS software modified the tooth profile to the shape of a trapezoid with concave working surface. [3,4] The radius outline was enlarged by $5 \%$ respective of the operating radius of the drive wheel tooth. The described design solution reduced the surface pressure calculated by Hertz formulas. Contact stresses were also reduced to about $1500 \mathrm{MPa}$, while in the former Eicotrack system they exceeded $2500 \mathrm{MPa}$. [5] The lower value of contact stresses prolongs the operating time of the drive wheel, which results in cost savings associated with downtime. Consequently it has a great impact on the level and cost of coal mining.

\section{Numerical analysis of the newly developed Flextrack module}

Due to the possible occurrence of short-term critical values of the exciting forces, a double value of the safety factor was adopted in the main guidelines for the examined material. As a result of laboratory tests, the cast L20HGSNM steel with increased resistance to abrasion wear was selected as a material for further studies. For the predetermined period of time, a numerical simulation of the drive wheel operation was carried out, including its meshing with teeth arranged in the guide on a distance of $140 \mathrm{~mm}$. The estimated maximum stress reached during the numerical analysis by the wheel moving on racks exceeded $557 \mathrm{MPa}$. Figure 1 shows the distribution of the fields of reduced stress under the preset loading conditions.

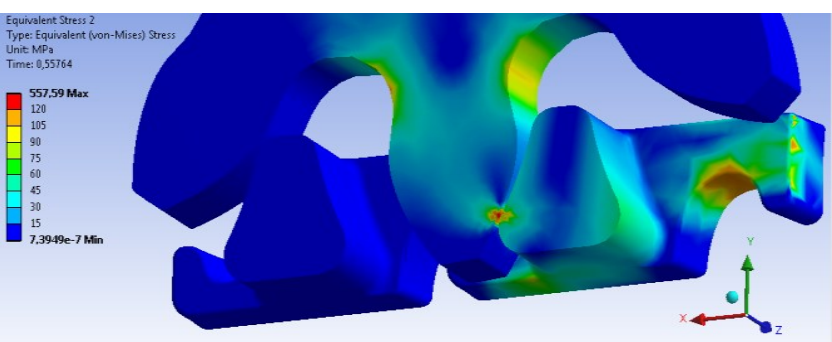

Fig. 1. The distribution of the fields of reduced stress during meshing in the preset time step of the drive wheel teeth with teeth spaced in the guide

Based on the results of numerical computations, in the areas with maximum values of reduced stress, the components of the stress tensor were generated. Figure 2 graphically depicts changes in the normal stress and displacement components at points P1 and $\mathrm{P} 2$. Point $\mathrm{P} 1$ is positioned on the lower surface of the side arm subjected to compressive forces operating on the inside and extending to the outside of the arm. Point P2 is dominated by tensile stresses operating in the lower part of the radius connecting the working surface of the rack with the side surface of the guide arm.
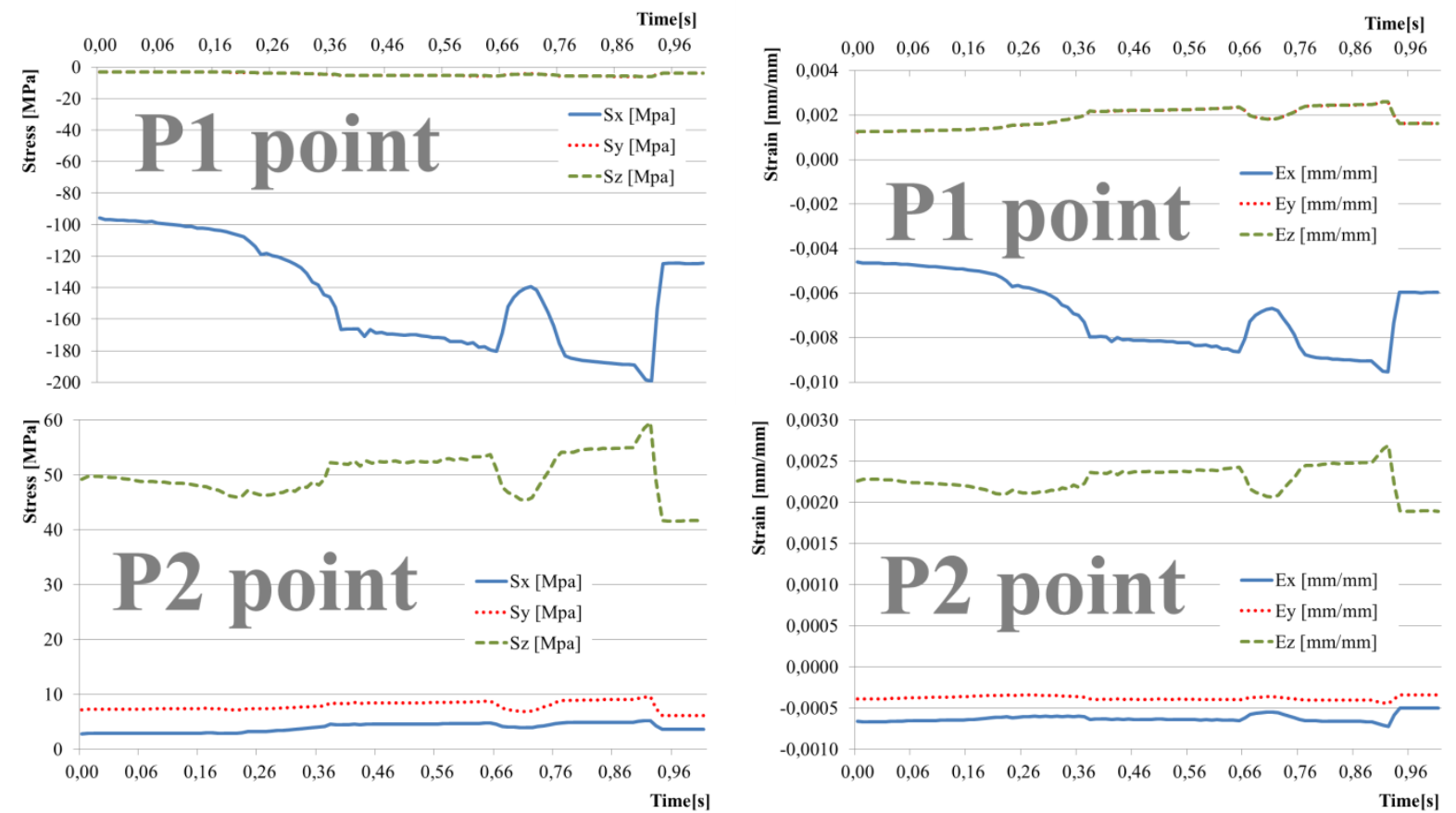

Fig. 2. Changes of the stress and displacement tensor components occurring in the preset time step in a model rack 


\section{Determination of fatigue life for a model rack}

Structures are generally subjected to the effect of variable loads. The estimation of structure durability requires analysis of the state of multiaxial loads, but fatigue tests are mostly conducted under the conditions of uniaxial loads. It is also required to experimentally determine the material characteristics and have knowledge of the stress and strain components in the examined element. To achieve this purpose, for the state of multiaxial fatigue, the relevant criteria are applied which, by combining the stress and strain components, enable reducing the spatial state to a uniaxial one used in the fatigue life determination based on standard tests. Another possibility is to use a predetermined value of the deformation energy. One of the multiaxial fatigue criteria is based on the idea of the, so called, critical plane. The stresses and strains experienced by this plane give rise to the formation of a fatigue crack. Thus the plane can be considered a determinant of the crack origin, which makes it very useful in the high cycle fatigue test (HCF), although numerous studies indicate its applicability also in the low cycle fatigue test (LCF). [6]

The numerical analysis allows determining the stress and strain components in the tested structure. The numerical description of the examined material usually assumes a linear characteristic in the range of elastic strains or, additionally, the stress - strain relationship in a range above the yield point. In the case of the rack cast from the L20HGSNM steel, in addition to the material characteristics determined in static tensile test, also fatigue characteristics were determined. Fatigue tests were performed with the increasing amplitude of force, operating in a mode analogical to the modified low cycle test (MLCF). [7] Due to small differences between the values of $R_{0.2}$ and $R_{m}$, the load increment was considerably concentrated in this range.

\section{Overview of some fatigue criteria}

The prevalence of complex states of stress in all kinds of cyclically loaded structures creates interest in the study of timevarying spatial states of stress and encourages formulation of multiaxial fatigue criteria. The most commonly applied type of classification is the division into criteria based on deformation, stress and energy. There are different ways of systematizing these criteria, to mention as an example the division proposed in [8] into the experimental and global criteria with subdivision into the criteria based on the invariants of the state of stress, on energy and on integrals, and also based on the concept of the, so-called. critical plane. The latter ones are increasingly being used in the range of both low and high number of cycles for which they were originally set. [9] The determination of the triaxial fatigue criterion is subject to the below mentioned points:

1. The triaxial criterion should be equally well applicable in a uniaxial state of stress.

2. The direction of crack propagation predicted by the criterion should be consistent with the experimental data.

3. The triaxial fatigue criterion should be expressed by a mathematical formula similar to the uniaxial criterion to enable the determination in a classical uniaxial fatigue test of all the necessary coefficients present in the equation.

The following briefly discusses the use of the multiaxial criterion of principal strain in fatigue life prediction along with the uniaxial Manson-Coffin-Morrow criteria and the SmithWatson-Topper criterion:

\section{Coffin-Morrow (C-M) criterion}

The basic Coffin-Morrow equation defining the fatigue life criterion in a uniaxial state of stress has the following form:

$\frac{\Delta \varepsilon_{s p}}{2}+\frac{\Delta \varepsilon_{p l}}{2}=\frac{\sigma_{f}^{\prime}}{E}\left(2 N_{f}\right)^{b}+\varepsilon_{f}^{\prime}\left(2 N_{f}\right)^{c}$

where:

$$
\begin{aligned}
& \varepsilon_{\mathrm{pl}}-\text { plastic strain, } \\
& \varepsilon_{\mathrm{sp}}-\text { elastic strain, } \\
& 2 \mathrm{~N}_{\mathrm{f}}-\text { number of cycles, } \\
& \varepsilon_{\mathrm{f}}-\text { fatigue ductility coefficient, } \\
& \sigma_{\mathrm{f}}-\text { fatigue strength coefficient, } \\
& \mathrm{b}-\text { fatigue strength exponent, } \\
& \mathrm{c}-\text { fatigue ductility exponent, } \\
& \mathrm{E}-\text { Young's modulus. }
\end{aligned}
$$

Equation (1) does not allow for the effect of mean stress $\sigma_{\mathrm{m}}$, which can be introduced using the, so-called, Morrow correction:

$$
\frac{\Delta \varepsilon_{s p}}{2}+\frac{\Delta \varepsilon_{p l}}{2}=\frac{\sigma_{f}^{\prime}-\sigma_{m}}{E}\left(2 N_{f}\right)^{b}+\varepsilon_{f}^{\prime}\left(2 N_{f}\right)^{c}
$$

This criterion is based on the observations that mean stress plays an important role when the principal component is derived from elastic strain.

\section{Brown-Miller strain criterion}

The Brown-Miller equation proposes that the maximum fatigue damage occurs on the plane which experiences the maximum shear strain amplitude, and that the damage is a function of both this shear strain and the strain normal to this plane.

$$
\begin{aligned}
& \frac{\Delta \gamma_{\max }}{2}+\frac{\Delta \varepsilon_{n}}{2}=C_{1} \frac{\sigma_{f}^{\prime}}{E}\left(2 N_{f}\right)^{b}+C_{2} \varepsilon_{f}^{\prime}\left(2 N_{f}\right)^{c} \\
& \gamma_{\max }-\text { maximum shear strain, } \\
& \varepsilon_{\mathrm{n}}-\text { strain normal to the maximum shear strain. }
\end{aligned}
$$

For elastic stresses $v=0,3$ and $\mathrm{C} 1=1,65$. For the plastic value of Poissons ratio of 0,5 the constant $\mathrm{C} 2=1,75$. The constant $\mathrm{C} 1$ and $\mathrm{C} 2$ were derived on the assumption that cracks initiate on the plane of maximum shear strain. The Brown-Miller equation gives the most realistic life estimates for ductile metals, and tends to be nonconservative for brittle metals.

\section{Smith-Watson-Topper (S-W-T) criterion}

The SWT criterion does not have the above mentioned limitations related to the range of strain and as such assumes the following form: 
$\frac{\Delta \varepsilon_{s p}}{2} \sigma_{\max }+\frac{\Delta \varepsilon_{p l}}{2} \sigma_{\max }=\frac{\left(\sigma_{f}^{\prime}\right)^{2}}{E}\left(2 N_{f}\right)^{2 b}+\sigma_{f}^{\prime} \varepsilon_{f}^{\prime}\left(2 N_{f}\right)^{b+c}$

where:

$\sigma_{\max }-$ the maximum stress for hysteresis

\section{The criterion of principal strain}

This criterion assumes that fatigue cracks develop perpendicularly to the plane on which the amplitude of principal strain $\Delta \varepsilon_{1}$ is the largest. In the case of a uniaxial state of stress, the maximum vector size of the principal strain assumes the same direction as the maximum axial strain. The replacement of axial strain in a Coffin-Morrow uniaxial fatigue criterion with the amplitude of principal strain changes this criterion into a triaxial form.

$$
\frac{\Delta \varepsilon_{1 s p}}{2}+\frac{\Delta \varepsilon_{1 p l}}{2}=\frac{\sigma_{f}^{\prime}}{E}\left(2 N_{f}\right)^{b}+\varepsilon_{f}^{\prime}\left(2 N_{f}\right)^{c}
$$

The criterion of principal strain can be successfully used in studies of the brittle materials, including cast iron and highstrength iron alloys. It does not apply to alloys characterized by high ductility, because it dangerously overestimates the fatigue life compared with experimental results. [10]

\section{Methodology for fatigue life determination}

The proposed methodology of transition from the stage when the state of stress and strain is estimated by numerical analysis to the stage when the fatigue life is estimated includes the following steps:

1. Description of material based on the static tensile test.

2. Low cycle fatigue tests carried out in standard (LCF) and modified mode (MLCF).

3. Verification of the obtained results and their implementation to model sample on which the numerical cyclic loading has been performed to check the correctness of the adopted properties.

4. Development of a discrete model of the rack, including model of material data defining the impact of assumed load on structure fatigue behaviour.

5. FEM computations to determine the components of the stress and strain tensor.

6. Interpretation of the obtained results of numerical computations and adopting the appropriate multiaxial fatigue criterion.

7. Determination of fatigue life of the rack, based on the obtained numerical values of deformation and fatigue life curve plotted for the cast L20HGSNM steel.

\section{Fatigue tests performed by the LCF method and its modified MLCF variant}

For fatigue testing by the LCF method, circular samples of a $6.5 \mathrm{~mm}$ diameter were prepared. The samples were subjected to symmetrical cyclic loading with different strain amplitudes selected from the preset range of plastic strains. Using the results of conducted test, the kinematic hardening was determined by determining the shift of the yield surface centre under the effect of the field of stresses using the back stress tensor $X_{i j}$. The size of this area during the translation does not change, and depends only on the trajectory on the operating stress. In the case of an isotropic hardening, changes in the flow stress are a function of the plastic strain. Characteristics of this hardening process are usually given in the form of a table comprising the numerical data combined in pairs expressing the flow stress and the corresponding plastic strain. In the case of kinematic hardening, the same data is given for a half-cycle, or when the entire hysteresis loop is used, the following relationships consistent with the Ziegler hypothesis apply [6]:

$X_{i j}^{\prime}=C \frac{1}{\sigma^{o}}\left(\sigma_{i j}-X_{i j}\right)^{\varepsilon_{i j}^{v p}}, \quad C=\frac{\sigma-\sigma^{o}}{\varepsilon^{p}}, X_{i j}^{\prime}=\sum_{k=1}^{N} X_{i j(k)}$

where:

$\mathrm{X}_{\mathrm{ij}}$ - increment in back stress $\mathrm{X}_{\mathrm{ij}}$,

$\mathrm{C}$ - modulus of the kinematic hardening,

$\sigma^{0}$ - flow stress describing the yield surface,

$\varepsilon^{\mathrm{vp}}{ }_{\mathrm{ij}}$ - the rate of plastic strain,

$\varepsilon^{\mathrm{p}}$ - plastic strain.

To define some selected mechanical properties, a modified low cycle fatigue test (MLCF) [7, 11] was carried out, based on which the amplitude of the stress cycle $\sigma_{\mathrm{a}}$ was determined, as well as the true plastic strain $\varepsilon_{\mathrm{p}}$ (caused by $2 \mathrm{~N}_{\mathrm{f}}$ load cycles) described by the Manson-Coffin-Morrow relationship:

$\sigma_{\mathrm{a}}=\mathrm{K}^{\prime}\left(\varepsilon_{\mathrm{p}}\right)^{\mathrm{n}}$,

$\sigma_{\mathrm{a}}=\sigma_{\mathrm{f}}^{\prime}\left(2 \mathrm{~N}_{\mathrm{f}}\right)^{\mathrm{b}}$

$\varepsilon_{\mathrm{p}}=\varepsilon_{\mathrm{f}}^{\prime}\left(2 \mathrm{~N}_{\mathrm{f}}\right)^{\mathrm{c}}$

where:

$\sigma_{\mathrm{f}}^{\prime}$ - fatigue strength coefficient approximately equal to $R_{m}$, $\varepsilon_{\mathrm{f}}$ - fatigue ductility coefficient under the operating stress $\sigma_{\mathrm{f}}^{\prime}$, $2 \mathrm{~N}_{\mathrm{f}}$ - the number of load cycles leading to sample fracture, $\mathrm{K}^{\prime}$ - cyclic strength coefficient,

$\mathrm{n}^{\prime}$ - cyclic strain hardening exponent,

$\mathrm{c}$ - fatigue ductility exponent.

The fatigue limit $\mathrm{Z}_{\mathrm{go}}$ was determined from the experimental curve plotted in Figure 3, applicable in the estimation of fatigue life of numerous metallic materials. [12] The obtained values were next used for the calculation of fatigue test parameters.

In the modified low cycle fatigue test (MLCF), the determination of selected parameters $\left(b, c, n ', K\right.$ and $\left.\varepsilon_{\max }\right)$ is based on the assumptions described in detail in [7, 11, 12], taking into account the possibility of using unilateral cycles to eliminate the 
occurrence of disorders in a uniaxial state of the stress field. The main advantage of the MLCF method is the ability to determine the mechanical properties on one sample only. Additionally, the following assumptions are adopted:

1. The relationship between plastic strain and amplitude under the low cycle test conditions is the same as the relationship which occurs between the strain on failure and amplitude. The plastic strain observed after 20 cycles changes little or does not change at all with further increase in the number of cycles.

2. The course of the straight line expressing the stress cycle amplitude $\sigma_{\mathrm{a}}$ calculated from equation (8) in a double logarithmic scale is determined by the position of points with the following coordinates: $\left[\begin{array}{llll}\ln & 20, & \ln & \mathrm{R}_{\mathrm{m}}\end{array}\right]$ and $\left[\ln \left(2 \mathrm{~N}_{\mathrm{f}}\right), \ln \left(\mathrm{Z}_{\mathrm{go}}\right)\right]$. Similarly, the straight line of the true plastic strain $\varepsilon_{\mathrm{p}}$ determined from equation (9) is based on the position of points with the following coordinates: $\left[\ln 20, \ln \varepsilon_{\mathrm{f}}\right]$ and $\left[\ln \left(2 \mathrm{~N}_{\mathrm{f}}\right), \ln \varepsilon_{\mathrm{z}}\right]$.

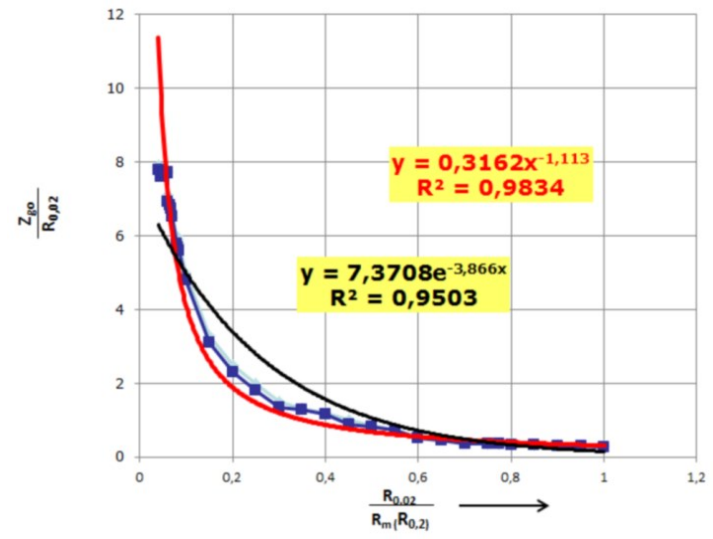

Fig. 3. An experimental curve to determine the fatigue strength of alloys [7]
Using samples similar to the LCF samples, tests were carried out by the modified MLCF method, assuming positive-pulsating load cycle with the increasing amplitude of stress, preserving small increments in loading force within the whole range of plastic strain. A characteristic curve describing changes in the stress-strain diagram is shown in Figure 4.

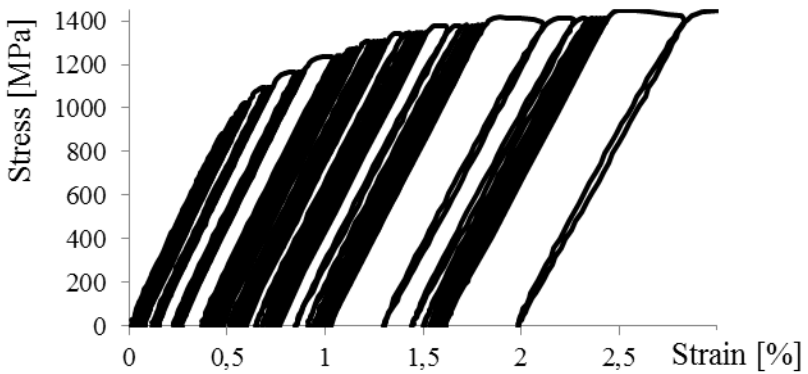

Fig. 4. Plastic strain changing in the MLCF test as a function of load increment

Using data obtained in the static tensile test and data obtained in the MLCF test, the following mechanical characteristics of the cast L20HGSNM steel were specified: $\mathrm{R}_{\mathrm{m}}$ - tensile strength, $\mathrm{R}_{0.2}$ yield strength, $\mathrm{R}_{0.02}$ - apparent elastic limit, $\mathrm{E}$ - modulus of elasticity, $\mathrm{A}_{5}$ - elongation, $\mathrm{Z}_{\mathrm{go}}$ - fatigue strength in rotary bending $\varepsilon_{\max }-$ the maximum permanent strain at $10^{7}$ cycles, and the exponents: fatigue strength $-\mathrm{b}$ and fatigue ductility $-\mathrm{c}$. Based on the obtained values of the exponents $\mathrm{b}$ and $\mathrm{c}$, the curve of the high cycle fatigue life was plotted. The resulting curve allowed comparing the maximum value of deformation allowed for the tested material under the preset number of operating cycles with the maximum strain obtained in a numerical model of the examined structure.

Table 1. The mechanical properties of cast L20HGSNM steel obtained in static tensile test and modified MLCF test

\begin{tabular}{|c|c|c|c|c|c|c|c|c|}
\hline $\begin{array}{c}\mathrm{R}_{\mathrm{m}} \\
{[\mathrm{MPa}]}\end{array}$ & $\begin{array}{c}\mathrm{R}_{0,2} \\
{[\mathrm{MPa}]}\end{array}$ & $\begin{array}{c}\mathrm{R}_{0,02} \\
{[\mathrm{MPa}]}\end{array}$ & $\begin{array}{c}\mathrm{E} \\
{[\mathrm{MPa}]}\end{array}$ & $\begin{array}{c}\mathrm{A}_{5} \\
{[\%]}\end{array}$ & $\begin{array}{c}\mathrm{Z}_{\mathrm{GO}} \\
{[\mathrm{MPa}]}\end{array}$ & $\begin{array}{c}\varepsilon_{\max } \\
{[\mathrm{mm} / \mathrm{mm}]}\end{array}$ & $\mathrm{b}$ & $\mathrm{c}$ \\
\hline 1446 & 1210 & 970 & 185000 & 7,1 & 528 & 0,00385 & $-0,077$ & $-0,182$ \\
\hline
\end{tabular}

Now, by comparing the reduced state of strain in selected area of the examined discrete model of rack with the fatigue life curve, the fatigue life of the examined structure can be estimated. According to the adopted hypothesis, the state of strain in the examined part of structure can be attributed to the reduced equivalent strain, or if there is one component dominating over other components, it can be identified with this component.

The numerical analysis allowing for the effect of operational loads acting on the cast steel rack has shown that the maximum strain observed in the numerical model had a value of less than $0.1 \%$, and was nearly four times lower than the permissible value estimated by fatigue test.

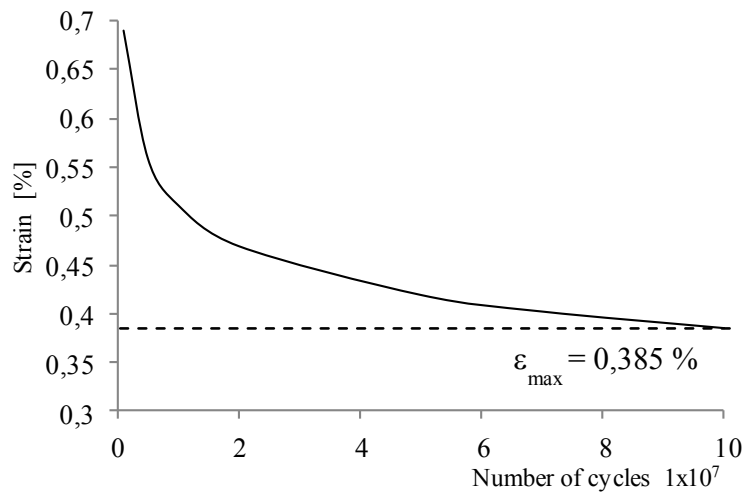

Fig. 5. Fatigue life curve plotted for the cast L20HGSNM steel. 


\section{Conclusion}

The methodology described in this study, based on the simultaneous engagement of experiment and numerical computations, involves the use of maximum permissible strain specified for the maximum number of cycles corresponding to the fatigue limit. The characteristic strain parameters determined as a function of the preset number of cycles operating in both low and high regime are compared to the strain obtained by numerical computations in these areas of the examined structural element where the highest loads are applied. In the case under discussion, only one component was dominating, and its value was directly adopted in the determination of equivalent strain. This type of reasoning is possible in all those cases where the origin of fatigue crack is on the surface of the examined element. In more complex structures, other relevant strain criteria have to be used.

\section{Acknowledgements}

The work was supported from the statutory activity no. 11.11.170.318 of the Faculty of Foundry Engineering, AGH University of Science and Technology

\section{References}

[1] Pysz, S. \& Piekło, J. (2013). The Application of Integrated Computational Materials Engineering (ICME ) in Foundry Practice. Transactions of Foundry Research Institute. LIII(4), 57-69.

[2] Sikora, W. (2005). Dynamic load in pulling systems high efficiency longwall shearers. Silesian University of Technology, Gliwice. (in Polish).
[3] Zawora, J. (2001). Fundamentals of Machine Technology. Warszawa: WSiP. (in Polish).

[4] Pysz, S., Małysza, M. \& Piekło, J. (2014). The Use of Topology Optimization in Shaping the Strength of Castings. Solid State Phenomena. 223, 62-69.

[5] Zachura, A. \& Żuczek, R. (2014). Innovative design of a longwall shearer's haulage system with highly loaded components of a tribological pair manufactured according to the precise casting technology. Solid State Phenomena. 223, 171-180.

[6] Karolczuk, A. \& Macha, E. (2005). A review of critical plane orientations in multiaxial fatigue failure criteria of metallic materials. International Journal of Fracture. 134, 267-304.

[7] Maj, M. (2012). Fatigue life of selected casting alloys. Dissertation. Katowice-Gliwice: Wyd. Archives of Foundry Engineering. (in Polish).

[8] Weber, B., Labesse-Jied, F., Robert, J.L. (2001). Comparison of multiaxial high cycle fatigue criteria and their application to fatigue design of structures. In Proceedings of the sixth International Conference on Biaxial/Multiaxial Fatigue \& Fracture, (Vol. 1), 195-202, Lisboa, Instituto Superior Tecnico.

[9] You, B.R. \& Lee, S.B. (1996). A critical review on multiaxial fatigue assessments of metals. International Journal of Fatigue. 18(4), 235-244.

[10] Jing, Li, Chun-Wang, Li, Yan-Jiang, Qiao \& Zhong-Ping Zhang. (2004). Fatigue life prediction for some metallic materials under constant amplitude multiaxial loading. International Journal of Fatigue. 68, 10-23.

[11] Maj, M. (2005). Use of a modified low cycle fatigue test to determine the mechanical properties of ADI at room and elevated temperature. Research project: 4 T08B 00625 , AGH Kraków. (in Polish).

[12] Maj, M. \& Piekło, J. (2009). MLCF - an optimised program of low - cycle fatigue test to determine mechanical properties of cast materials. Archives of Metallurgy and Materials. 54 (2), 393-397. 